\title{
Estimates of Induced Abortion in Mexico: What's Changed Between 1990 and 2006?
}

\section{By Fatima Juarez, Susheela Singh, Sandra G. Garcia and Claudia Diaz Olavarrieta}

Fatima Juarez is professor of demography, El Colegio de Mexico, and senior fellow, Guttmacher Institute, based in Mexico City. Susheela Singh is vice president for research, Guttmacher Institute, New York. Sandra G. Garcia is director, Population CouncilMexico, Mexico City. Claudia Diaz Olavarrieta is senior researcher, Instituto Nacional de Salud Pública, Mexico City.

A critical challenge in the global effort to reduce maternal mortality is the persistence of unsafe abortion, which accounts for $13 \%$ of pregnancy-related deaths worldwide. ${ }^{1}$ The World Health Organization defines unsafe abortion as a procedure to terminate an unintended pregnancy that is performed by an individual who lacks adequate skills or that occurs in conditions that do not meet basic medical standards, or both. ${ }^{2}$ Unsafe abortion has significant negative effects on women, families, public health systems and society worldwide ${ }^{3,4}$ and in Mexico ${ }^{5-7}$-yet it is almost entirely preventable.

Unsafe abortion is often the only option available to women who wish to terminate a pregnancy in countries where abortion is illegal or legally restricted, or where significant access barriers exist. Latin America and the Caribbean have some of the world's most restrictive abortion laws, yet an estimated 4.1 million abortions occur each year in this region, almost all of them unsafe. ${ }^{8}$ In Guatemala, where abortion is legal only to save the woman's life, the estimated annual abortion rate is 24 per 1,000 women aged $15-49$, and approximately $30 \%$ of all women having induced abortions are hospitalized for treatment of complications. ${ }^{9}$ In Mexico, complications from unsafe abortion are the fifth leading cause of maternal mortality (accounting for 6-8\% of pregnancy-related deaths); given the underreporting of maternal deaths in general and abortion deaths in particular, this proportion could be larger. ${ }^{10,11}$

Estimates of the incidence of unsafe abortion are critical for quantifying the scope of the problem and for informing policy change, ${ }^{12}$ yet there is little reliable information on trends in abortion incidence. In countries such as Mexico, where abortion is highly legally restricted, collecting accurate data is a formidable challenge, particularly given the limitations of face-to-face surveys and other direct measurement approaches. Although some national surveys have included abortion questions in pregnancy histories, the use of face-to-face interviews is likely to result in high levels of underreporting because of the stigma attached to abortion. ${ }^{13}$ Survey-based estimates show that the proportion of ever-pregnant women of reproductive age who have ever experienced a pregnancy loss has declined slightly, from 23\% in the 1987 Mexico Demographic and Health Survey (DHS) to 19-20\% in the National Survey of Demographic Dynamics for 1992 and 1997 and the National Survey of Reproductive Health for 2003. ${ }^{14}$ However, for several reasons these results are not definitive evidence that the level of induced abortion has declined. The 1987 DHS comes from a different survey series, and on a sensitive topic such as abortion, this may result in different levels of underreporting. Furthermore, the pregnancy loss prevalence measures include both spontaneous and 
induced abortions; given the rise in use of contraceptives since the 1980s and the increase in overall prevention of pregnancies, the proportion who have ever had a spontaneous abortion has likely declined. Together, these reasons may account for the apparent population-level decline in the proportion of women who have ever experienced a pregnancy loss.

In light of these problems with survey data, indirect estimates are an important tool, and different methodologies have been developed and tested. ${ }^{13,15}$ In the early 1990s, a novel indirect methodology was developed and used to estimate abortion incidence in six Latin American countries, including Mexico, based on hospital admissions data. ${ }^{16}$ This methodology has since been used successfully in other developing countries in Asia, Africa, and Latin America and the Caribbean. ${ }^{9,17-21}$ Using 1990 data for Mexico, Singh and Wulf estimated that 533,000 induced abortions occurred annually, and that the abortion rate was 25 per 1,000 women aged $15-44 .{ }^{* 16}$ No similar national estimate of abortion incidence has been made for Mexico since their study.

Not only has it been nearly 20 years since those estimates were calculated, but there is some evidence that misoprostol is increasingly being used as an abortifacient in Mexico. ${ }^{22,23}$ Marketed as Cytotec, the drug is a synthetic analogue of the prostaglandin El. It entered the global market in the late 1980s and is now registered for this use in more than 80 countries in the Western Hemisphere, Europe and South Asia. ${ }^{24}$

In Mexico, misoprostol was first marketed and sold in 1985, but was found to be little known in a study fielded in the early 1990s. ${ }^{23}$ Preliminary findings from a recent study of pharmacies in eight Mexican cities showed that in 2007 , between $50 \%$ and $87 \%$ of responding pharmacists knew about the use of misoprostol or Cytotec as an abortifacient; this proportion had been much lower only a few years earlier (39\% in a 2003 Mexico City study and $36 \%$ in a 2005 Morelos study). ${ }^{25}$ No published studies have measured national public awareness of misoprostol as an abortifacient, but pharmaceutical data indicate that national sales of misoprostol in Mexico increased almost threefold between 1985 and 2000, and then declined about 20\% between 2000 and 2006. ${ }^{26}$ The increase in sales through pharmacies (hospitals have a separate mechanism for purchasing drugs), coupled with the fact that misoprostol has not been the drug of choice to treat gastric ulcers in Mexico, suggests that misoprostol is often purchased for use as an abortifacient. Currently, although a prescription is legally required, in practice misoprostol is readily available over the counter, but at a relatively high cost-a bottle of 28 pills costs approximately US $\$ 130$. While administration of the drug may vary, an effective regimen for early pregnancy interruption would cost about US\$70. However, there is evidence from a recent

*This estimate was recalculated for women aged $15-44$, as the original rate was for those aged 15-49. study in Mexico that it is often sold on a pill by pill basis, which may explain the drop in sales. ${ }^{22}$

The present study provides new national and regional estimates for 2006. It uses the same methodology as the 1990 study, but adapts those methods when necessarymost importantly by incorporating the use of misoprostol to induce abortion, a practice that was rare in the earlier survey period. This approach provides for comparability, and enables us to assess trends in induced abortion in Mexico over the past decade and a half. In addition to looking at changes in abortion incidence between 1990 and 2006, we examine patterns in hospitalization due to abortion-related complications, a key indicator of morbidity resulting from unsafe abortion. Finally, we explore the relationship between contraceptive use and differences in abortion incidence among the four regions and at the national level, and discuss the broader relevance and implications of our findings.

\section{DATA AND METHODS}

\section{Data Sources}

We used two data sources for estimating abortion incidence: hospital discharge data on the number of women treated for abortion complications in 2006, and a survey of key informants who were knowledgeable about abortion provision in Mexico to obtain an estimate of the proportion of women who get abortions who are hospitalized. - Hospital discharge data. Data from Mexico's National System of Health Information (Sistema Nacional de Información en Salud) on the number of women treated in publicsector hospitals for abortion complications in 2006 were aggregated for seven hospital systems (see Web site Appendix at http://www.guttmacher.org/pubs/ifpp/appendix/ 3404.pdf). ${ }^{27}$ We examined the data for quality and completeness and to ensure comparability with data for 1990. To obtain a count of patients treated for postabortion complications in 2006 that was comparable to the count used in 1990, we selected the appropriate diagnostic codes from the new ICD-10 classification system that matched those from the earlier ICD-9 system. The previous study had made other adjustments to the hospital discharge data to account for misclassification of codes; ${ }^{16}$ because the 2006 data are of higher quality, these adjustments were not necessary.

The sources of health systems data on hospital care changed between 1990 and 2006: In 2006, the number of women hospitalized for abortion complications was obtained from three sources (outpatient, inpatient and emergency cases), whereas a single source was used in 1990 (only inpatient cases were available at that time). The total number of women treated for abortion complications (resulting from spontaneous or induced abortion) in all components of the public-sector hospital system in 2006 was 194,774 (112,978 reported inpatients, 26,823 reported outpatients and 54,973 estimated emergency cases; see Appendix Table 1).

- Health Professionals Survey. The Health Professionals Survey (HPS) was designed to assess the conditions of 
abortion provision in Mexico by eliciting the perceptions of knowledgeable key informants. We used the survey from the 1994 study, with some modifications, such as the addition of questions on misoprostol use (see Appendix). The survey provided information that was used to calculate a value ("the multiplier") accounting for the proportion of women who have induced abortions but either experience no complications or experience complications but do not obtain treatment in a public-sector hospital (some of whom may have died before reaching a hospital). The survey asked respondents to estimate the percentage distribution of all women seeking abortion according to type of provider, the probability that women would experience complications requiring medical care according to type of provider and the probability that women who need medical care would receive it from a public-sector hospital (see below and Appendix).

The HPS was fielded from January to September 2007. Field staff interviewed a total of 132 health professionals in five states (Baja California, Chiapas, Guanajuato, Veracruz and Yucatán) and Mexico City (Distrito Federal); these states and the federal district were chosen because they represent the major regions of Mexico and reflect distinct socioeconomic and geographic characteristics that are likely to be related to conditions of abortion provision. The country does not have an official definition of major regions, so we used that developed by the National Population Council (Consejo Nacional de Población); this definition is based on a measure of social and economic disadvantage that incorporates indicators of household amenities and services, educational attainment and income. ${ }^{28}$ With a few exceptions, states' geographic locations coincide with their assigned regions. ${ }^{*}$ The four regions are Mexico City, North (represented by Baja California), Central (represented by Guanajuato and Yucatán) and South/East (represented by Chiapas and Veracruz). These regions can be correlated with hospital systems data, since the latter are available for each state.

- Sources for contraceptive use, unmet need and pregnancy intention. Data on contraceptive use, pregnancy intention and unmet need for contraceptive services were obtained from three national surveys, the National Survey of Demographic Dynamics (ENADID), for 1992, 1997 and 2006. ${ }^{29-31}$ Because of data constraints, we were able to es-

*States in each region-North: Aguascalientes, Baja California, Baja California Sur, Chihuahua, Coahuila, Colima, Jalisco, Mexico, Nuevo León, Sonora and Tamaulipas (more developed). Central: Campeche, Durango, Guanajuato, Michoacán, Morelos, Nayarit, Puebla, Querétaro, Quintana Roo, San Luis Potosí, Sinaloa, Tabasco, Tlaxcala, Yucatán and Zacatecas (less developed). South/East: Chiapas, Guerrero, Hidalgo, Oaxaca and Veracruz (least developed). Mexico City (Distrito Federal) is the most developed region.

tMiscarriages at $13-21$ weeks account for $2.89 \%$ of all pregnancies that are recognized starting at six weeks' gestation; since live births are $84.8 \%$ of all recognized pregnancies, such miscarriages are equal to $3.41 \%$ of all live births (2.89\%/84.8\%; source: reference 32$)$. The number of live births in 2006 was 1,982,565 (source:Consejo Nacional de Población (CONAPO), Proyecciones 1970-2030, Mexico City: CONAPO, 2006).

\#Calculated as $3.41 \% \times 66.7 \% \times 1,982,565=45,097$. timate unmet need only for 1997 and 2006. Data on the planning status of births were not collected for 2006, so we used data for current pregnancies. These surveys were nationally representative and interviewed women aged 15-54; the sample sizes were 69,538 for 1992, 88,022 for 1997 and 41,133 for 2006.

\section{Estimating the Incidence of Induced Abortion}

-Women hospitalized for induced abortion. To calculate the incidence of induced abortion, we had to exclude women hospitalized for complications resulting from spontaneous abortions. Hospital data typically do not distinguish between induced and spontaneous abortions, partly because symptoms are often similar, and partly because of a reluctance to expose patients to potential legal repercussions. We used data on the average biological pattern of spontaneous pregnancy loss (based on clinical studies ${ }^{32}$ ) to indirectly estimate the proportions of women who experience late miscarriages (13-21 weeks of gestation), are likely to require hospital care and, if they receive care, would be included in the number of patients treated in hospitals for any abortion complications. Women who experience spontaneous pregnancy loss in the first trimester are assumed to generally not need hospital care and, if they do obtain medical care, to visit primary health care centers or private physicians (and thus not be included in the hospital data). Pregnancy losses at 22 or more weeks were not considered because they are classified as fetal deaths rather than abortions. After applying these assumptions, we estimated the number of late spontaneous miscarriages to be equivalent to $3.41 \%$ of all live births. ${ }^{\dagger}$ A further adjustment was needed because only a certain proportion of women who need hospital care for the treatment of late spontaneous pregnancy loss will obtain such services; we assumed this proportion to be the same as the proportion of women who deliver at a government facility. Nationally, $67 \%$ of women delivered at a public health facility- $68 \%$ in Mexico City, $71 \%$ in the North, $66 \%$ in the Central and $59 \%$ in the South/East. ${ }^{33}$

Hence, we estimated that the annual number of women hospitalized because of spontaneous abortion was $45,097 .^{\ddagger}$ The national number of women hospitalized for complications of induced abortion was therefore 149,677 (the difference between 194,774 and 45,097).

- Estimating the multiplier. The HPS provided the information we needed to estimate the proportion of women hospitalized among all of those who had induced abortions. As mentioned earlier, some women who have an abortion either do not need or do not obtain hospital treatment. In general, the safer abortion services are, the higher the multiplier, because for every woman receiving treatment, many have abortions that do not result in complications requiring medical care. Likewise, the less safe abortion services are, the lower the multiplier, because a higher proportion of women will have serious complications that require care. Safety is not the only consideration, 
however, as the multiplier also accounts for the accessibility of health facilities. Where facilities are easily accessible, the proportion of women with complications who receive treatment will be higher. In poor or underdeveloped regions, by contrast, some of the most seriously affected women may not get the treatment they need.

The steps in calculating the multiplier are summarized here (and detailed in the Appendix). Because conditions vary greatly by socioeconomic status and place of residence, these steps were carried out separately for each of four subgroups: urban poor and nonpoor, and rural poor and nonpoor.*

The HPS first asked respondents to estimate the distribution of all women obtaining abortions according to six types of "provider": misoprostol (regardless of who provided it) and, for all other methods, medical doctors or gynecologists, pharmacists, nurses or trained midwives, traditional birth attendants and the woman herself. This adaptation of the standard HPS question was necessary because misoprostol may be obtained from a range of sources, including most if not all types of providers. Second, respondents were asked to estimate the proportion of abortion patients who experience complications, by provider type.

By multiplying these two proportions, we were able to estimate the percentage expected to have complications from an abortion obtained from a given type of provider, among all women having abortions, for each socioeconomic subgroup (see Appendix Table 2). We then summed the expected percentages for the six provider types to obtain the overall percentage, among all women having abortions in each subgroup, who had abortion complications.

Third, HPS respondents were asked to estimate the proportion of women with complications who obtain care from a public-sector health facility (see Appendix Table 3). We applied this proportion to the percentage of women in each socioeconomic subgroup expected to have abortion complications. The four resulting percentages were then weighted by the relative size of the four groups nationally to arrive at a multiplier for the whole country.

Because direct experience in treating women with abortion complications may influence key informants' perceptions, we calculated the multiplier for two groups of respondents: the approximately $60 \%$ who were medical providers (those directly involved in clinical care) and the other $40 \%$ who were not providers (those working in health statistics, administration, research and advocacy). The results showed that medical providers perceived a greater probability of medical complications than did the others; similar findings have been observed in other Latin American countries. ${ }^{18}$ To adjust for this bias, the multipli-

* Poor and nonpoor were defined using the education level of women, as data on income are available only for those who work, and are not reliable. Nonpoor women were defined as those with 10 or more years of schooling, and poor women as those with nine or fewer years of schooling (source: reference 31). er was calculated by giving equal weight to the two groups (see Appendix).

These calculations produced a national multiplier representing the estimated proportion of women obtaining abortions who were hospitalized in public-sector facilities for treatment of complications. Following the indirect estimation methodology, we established a range of estimates within one unit of this multiplier, and also estimated low, medium and high multipliers for each region. The medium national multiplier was 5.84, with a low of 4.84 and a high of 6.84 (see Table 1). The range of multipliers for specific regions was 3.88-5.48 for the North, 4.02-5.68 for the South/East and 5.38-7.60 for the Central region. The much higher range of multipliers for Mexico City $(8.38-11.83)$ is plausible, given the expectation that access to safe abortion services is greatest in the capital city.

The total number of women having abortions was estimated by multiplying the number of women receiving treatment in public-sector hospitals for induced abortion complications by the relevant multiplier. Abortion rates and ratios at the national and regional levels were calculated using the above estimates and population and birth data from other sources. Results for regions were based on state-specific calculations, summed to produce regional estimates.

\section{Limitations}

Our methodology has a number of limitations. The indirect estimation technique we applied relies on the quality of hospital data and the accurate classification of women according to diagnostic codes. Data for 2006 hospital admissions were considered to be of higher quality and completeness than data available in 1990; nevertheless, the 2006 data on women treated for complications from unsafe abortion may still be slightly incomplete because of underreporting. Another limitation of this methodology is that we made key assumptions in our calculations. For example, the rate of spontaneous pregnancy loss is based on clinical studies conducted in the 1980s: Even though these biological patterns are relatively stable, they may have changed over the past 25 years in response to changes in diet, lifestyles and environmental conditions. Finally, to calculate the multipliers, we relied on a sample of health professionals to estimate the probability with which women experience abortion-related complications and seek care, in both rural and urban settings. While we are confident that we interviewed a diverse sample of health professionals who are knowledgeable about this topic, it is nevertheless a convenience sample and their responses were based on perceptions.

\section{RESULTS}

\section{Abortion Morbidity}

A total of 194,774 women were treated in public-sector hospitals for complications from induced or spontaneous abortions in 2006 (Table 1, page 6). After subtracting the estimated number of women hospitalized for complica- 
TABLE 1. Measures related to calculating the number of women hospitalized for complications of induced abortion, by region, Mexico, 2006

\begin{tabular}{|c|c|c|c|c|c|c|c|c|c|}
\hline \multirow[t]{2}{*}{ Region* } & \multicolumn{2}{|c|}{ No. of women aged 15-44 } & \multicolumn{2}{|c|}{ No. of women hospitalized } & \multicolumn{2}{|c|}{$\begin{array}{l}\text { Induced abortion hospitalization } \\
\text { rate per } 1,000 \text { women aged } 15-44\end{array}$} & \multicolumn{3}{|c|}{ Range of multipliers§ } \\
\hline & Unadjusted & Adjusted $\dagger$ & For sponta- & For induced & Unadjusted & Adjusted $\dagger$ & Low & Mediu & High \\
\hline All & $26,240,334$ & na & 194,774 & 149,677 & 5.7 & na & 4.84 & 5.84 & 6.84 \\
\hline Mexico City & $2,296,028$ & $4,857,996$ & 24,066 & 16,459 & 7.2 & 3.4 & 8.38 & 10.11 & 11.83 \\
\hline North & $10,488,106$ & $7,926,138$ & 74,063 & 59,791 & 5.7 & 7.5 & 3.88 & 4.68 & 5.48 \\
\hline Central & $8,398,208$ & na & 61,998 & 47,134 & 5.6 & na & 5.38 & 6.49 & 7.60 \\
\hline South/East & $5,057,992$ & na & 34,647 & 26,293 & 5.2 & na & 4.02 & 4.85 & 5.68 \\
\hline
\end{tabular}

*Regions were defined by their level of economic development:Mexico City (Distrito Federal) is the most economically developed; the North is less developed than Mexico City; the Central is less developed than the North; and the South/East is the least developed. Data were obtained for each of Mexico's 32 states and then summed. †To calculate rates and ratios, the base populations and number of births for two regions were adjusted. The population of the areas of the North that are part of the greater metropolitan area of Mexico City was added to that of Mexico City, because hospitals in Mexico City provide care for these areas. $\neq$ Unadjusted for base population and number of births. §The medium multiplier was derived from the Health Professionals Survey to account for women not hospitalized for treatment of complications. For the national values, the low and high multipliers are one unit below and above, respectively, the medium multiplier. Low and high multipliers for each region were estimated by applying the ratio between national multipliers (4.84:5.84 and 6.84:5.84, respectively) to each region's medium multiplier. Note: na=not applicable.

tions of spontaneous abortions in 2006 (45,097), the number of women hospitalized for complications of induced abortions was 149,677 . About $28 \%$ of these women were treated in emergency rooms, $14 \%$ as outpatients and the remaining 58\% as inpatients (not shown).

To allow comparisons over time and across regions in Mexico, we calculated the rate of hospitalization for induced abortion-the annual number of women hospitalized for treatment of induced abortion complications per 1,000 women aged 15-44. For 2006, this national rate was 5.7. Because women living in areas of the North region that are adjacent to the metropolitan area of Mexico City largely use the city's hospitals (which are nearer than those in their state capital), adjusted rates for Mexico City and the North were calculated accordingly by correcting the base populations for each region. Following this procedure, Mexico City had the lowest adjusted rate (3.4), which likely reflects safer abortion practices. Note that the unadjusted hospitalization rate-based on the population of Mexico City alone-was more than twice as large (7.2). This population adjustment also affected the rate for the North region: It was 5.7 without the correction, and a substantially higher 7.5 with the correction. This higher-than-average hospitalization rate suggests that unsafe methods are more likely to be used in the North, but also that women in this region, which is relatively more developed than the Central and South/East regions, are more likely to get hospital care when they have complications. In the Central region, which is characterized by a medium level of development, the hospitalization rate was similar to the national average (5.6), and in the South/East region, which includes the least developed states, the rate was somewhat lower (5.2), possibly related to poorer access to hospital care.

\section{Abortion Incidence}

Given the assumptions underlying the multiplier, the estimates should be interpreted and used as approximate measures with a range of variation. The medium 2006 estimate for the total number of induced abortions in Mexico was 875,000 (Table 2, rounding to the nearest 1,000); the low estimate was 725,000 , and the high estimate was $1,024,000$. The national medium estimate for the abortion rate was 33 induced abortions per 1,000 women aged 15-44 per year, with a low estimate of 28 and a high estimate of 39. The abortion rate was similar in three of the major regions: Mexico City, the North and the Central had medium rates of 34-36. The South/East had a substantially lower abortion rate of 25 .

TABLE 2. Estimated number of induced abortions, abortion rate and abortion ratio, by region, according to multiplier, 2006

\begin{tabular}{llll|lll|lll}
\multirow{2}{*}{ Region } & \multicolumn{3}{l}{ No. of induced abortions } & \multicolumn{3}{l}{ Abortion rate } & \multicolumn{2}{l}{ Abortion ratio } \\
\cline { 2 - 9 } & Low & Medium & High & Low & Medium & High & Low & Medium & High \\
\hline All & $\mathbf{7 2 5 , 0 7 0}$ & $\mathbf{8 7 4 , 7 4 7}$ & $\mathbf{1 , 0 2 4 , 4 2 4}$ & $\mathbf{2 8}$ & $\mathbf{3 3}$ & $\mathbf{3 9}$ & $\mathbf{3 7}$ & $\mathbf{4 4}$ & $\mathbf{5 2}$ \\
Mexico City & 137,145 & 165,455 & 194,875 & 28 & 34 & 40 & 42 & 51 & 59 \\
North & 230,710 & 278,336 & 325,962 & 29 & 35 & 41 & 39 & 47 & 55 \\
Central & 252,093 & 304,133 & 356,173 & 30 & 36 & 42 & 38 & 46 & 54 \\
South/East & 105,122 & 126,823 & 148,523 & 21 & 25 & 29 & 26 & 31 & 36
\end{tabular}

Notes: The abortion rate is the number of abortions per 1,000 women aged 15-44; the abortion ratio is the number of abortions per 100 live births. Multiplier accounts for women not hospitalized for treatment of complications. To calculate rates and ratios, the base populations and number of births for two regions were adjusted. The population of the areas of the North that are part of the greater metropolitan area of Mexico City was added to that of Mexico City, because hospitals in Mexico City provide care for these areas. 
The national medium estimate of the abortion ratio in 2006 was 44 abortions for every 100 live births; the low estimate was 37 and the high estimate was 52. The medium estimate corresponds to one abortion occurring for every 2.3 live births, or just under one of every three pregnancies (not shown). The medium abortion ratio was highest in Mexico City (51) and was 46-47 in the North and Central regions. It was lowest in the South/East, which had a ratio of 31, or about one abortion for every three live births, or one of every four pregnancies.

\section{Trends in Abortion Incidence, 1990-2006}

Nationally, the annual number of women hospitalized for induced abortion increased by $40 \%$ between 1990 and 2006, from 106,620 to 149,677 (Table 3). This increase was close to the growth rate of the population of women of reproductive age. In contrast, the hospitalization rate for induced abortion increased by only $6 \%$ (from 5.4 to 5.7 per 1,000 women) over this 16-year period. As reflected in the medium multipliers for $1990^{16}$ and 2006 (5.0 and 5.8, respectively), the proportion of women having abortions who had complications treated in hospitals declined only slightly over this period, from $20 \%$ to $17 \%$ (not shown). However, the medium national estimate of the number of women having abortions increased sharply, from 533,000 women in 1990 to 875,000 in 2006, an increase of $64 \%$. The national induced abortion rate increased 33\% between 1990 and 2006, from 25 per 1,000 women aged 15-44 to 33 per 1,000 women. A much larger increase was observed in the abortion ratio, which rose $110 \%$ over this period, from 21 per 100 live births to 44 . This steep increase was a result of a substantial decline in fertility combined with an increase in the abortion rate.

\section{Abortion in Context}

To understand the context in which induced abortion occurs in Mexico, it is important to examine overall demographic trends, and in particular, the levels and trends of contraceptive use and unmet need, and levels of unintended pregnancy. Mexico has experienced major demographic and social changes in recent decades. From 1970 to 2000 , its population doubled, urbanization proceeded rapidly ( $75 \%$ of the population is now urban) and the pro-
TABLE 3. National trends in abortion incidence and related measures, 1990-2006

\begin{tabular}{|c|c|c|c|}
\hline Measure & 1990 & 2006 & $\begin{array}{l}\% \\
\text { chang }\end{array}$ \\
\hline No. of women aged 15-44 & $19,592,576$ & $26,240,334$ & 34 \\
\hline \multicolumn{4}{|l|}{ No. of women hospitalized } \\
\hline For any abortion & 142,159 & 194,774 & 37 \\
\hline For spontaneous abortion & 35,539 & 45,097 & 27 \\
\hline For induced abortion & 106,620 & 149,677 & 40 \\
\hline \multicolumn{4}{|l|}{ Measures of abortion } \\
\hline No. of induced abortions & 533,098 & 874,747 & 64 \\
\hline \multicolumn{4}{|l|}{ Abortion rate (per 1,000} \\
\hline women aged 15-44) & $25^{*}$ & 33 & 33 \\
\hline Abortion ratio (per 100 live births) & 21 & 44 & 110 \\
\hline \multicolumn{4}{|l|}{$\begin{array}{l}\text { Induced abortion hospitalization } \\
\text { rate (per 1,000 women }\end{array}$} \\
\hline aged 15-44) & 5.4 & 5.7 & 6 \\
\hline \multicolumn{4}{|c|}{$\%$ of currently married women using contraceptivest } \\
\hline Any method & 63.1 & 70.9 & 12 \\
\hline Modern method & 55.2 & 66.2 & 20 \\
\hline Total fertility rate & 3.4 & 2.2 & -37 \\
\hline
\end{tabular}

*This estimate was recalculated for women aged $15-44$, as the original rate was for those aged 15-49. †The earlier year for these two measures is 1992. Sources: 1990 data —reference 16.1992 contraceptive use data —reference 29. 2006 contraceptive use and fertility data-reference 31 .

portion of women completing high school increased from $5 \%$ to $27 \% .^{34,35}$ There has also been a steady increase in contraceptive prevalence, from $25 \%$ in the late 1970 s to $71 \%$ in 2006 , with modern methods accounting for most of the contraceptive use in both periods. ${ }^{31,36,37}$ However, contraceptive prevalence varied substantially across regions in 2006, ranging from 81\% in Mexico City to 63\% in the South/East (Table 4).

Data for 2000 and 2006 suggest a likely increase in unintended pregnancy over this period: Among sexually active women aged 15-24, the proportion who were single increased over this period (from 23\% to 28\%); however, contraceptive use was very low among these young women (not shown). ${ }^{31,38,39}$ The increasing level of unmet need among sexually active adolescents has been highlighted as one of the main challenges currently facing the Mexican government. ${ }^{40}$

Between 1992 and 2006, use of modern contraceptive methods among currently married women aged 15-49 increased moderately, from $55 \%$ to $66 \%$. A similar trend was

\begin{tabular}{|c|c|c|c|c|c|c|c|c|c|c|c|c|c|c|c|}
\hline \multirow[t]{3}{*}{ Region } & \multicolumn{9}{|c|}{$\%$ of married women } & \multicolumn{3}{|c|}{$\begin{array}{l}\% \text { of users relying on } \\
\text { traditional methods }\end{array}$} & \multicolumn{3}{|c|}{$\begin{array}{l}\% \text { of women with } \\
\text { unmet need }\end{array}$} \\
\hline & \multicolumn{2}{|c|}{ Any method } & \multirow[b]{2}{*}{2006} & \multicolumn{3}{|c|}{ Modern method } & \multicolumn{3}{|c|}{ Traditional method } & \multirow[b]{2}{*}{1992} & \multirow[b]{2}{*}{1997} & \multirow[b]{2}{*}{2006} & \multirow[b]{2}{*}{1992} & \multirow[b]{2}{*}{1997} & \multirow[b]{2}{*}{2006} \\
\hline & 1992 & 1997 & & 1992 & 1997 & 2006 & 1992 & 1997 & 2006 & & & & & & \\
\hline All & 63 & 68 & 71 & 55 & 60 & 66 & 8 & 9 & 5 & 12 & 13 & 7 & $\mathbf{u}$ & 11.6 & 12.4 \\
\hline Mexico City & 76 & 78 & 81 & 69 & 71 & 77 & 7 & 7 & 5 & 10 & 9 & 6 & $\mathrm{u}$ & 5.8 & 5.4 \\
\hline North & 69 & 73 & 76 & 62 & 64 & 72 & 7 & 9 & 4 & 10 & 12 & 6 & $\mathrm{u}$ & 8.2 & 9.5 \\
\hline Central & 58 & 65 & 67 & 49 & 55 & 62 & 8 & 10 & 6 & 15 & 15 & 9 & $\mathrm{u}$ & 14.1 & 14.2 \\
\hline South/East & 54 & 60 & 63 & 45 & 52 & 59 & 8 & 8 & 4 & 16 & 13 & 6 & $\mathrm{u}$ & 17.3 & 18.0 \\
\hline
\end{tabular}




\begin{tabular}{|c|c|c|c|c|}
\hline Region & $\begin{array}{l}\% \\
\text { unwanted }\end{array}$ & $\begin{array}{l}\% \\
\text { mistimed }\end{array}$ & $\begin{array}{l}\text { Total } \% \\
\text { unintended }\end{array}$ & $\begin{array}{l}\text { Total } \\
\text { fertility } \\
\text { rate }\end{array}$ \\
\hline All & 12.1 & 14.8 & 26.8 & 2.17 \\
\hline Mexico City & 7.3 & 9.5 & 16.8 & 1.66 \\
\hline North & 12.2 & 14.6 & 26.7 & 2.16 \\
\hline Central & 13.4 & 16.9 & 30.3 & 2.22 \\
\hline South/East & 11.3 & 13.3 & 24.6 & 2.32 \\
\hline
\end{tabular}

Note: Based on women who reported that they were pregnant at the time of interview; data were not available for recent births. Source: reference 31 .

observed in all four regions. In contrast, traditional methods were not widely used: In 2006, the proportion of women using these methods was $5 \%$. Furthermore, the proportion of all contraceptive users who relied on traditional methods declined from 12\% in 1992 to 7\% in 2006.

Unfortunately, information on unmet need for contraception was available only from the ENADID surveys for 1997 and 2006. * Over this period, unmet need hardly changed, remaining at an estimated $12 \%$ among married women of reproductive age (11.6\% in 1997 and $12.4 \%$ in 2006). This level of unmet need is moderate, and is consistent with a high level of contraceptive use. The lowest level of unmet need was observed in Mexico City (5\%), followed by the North, the Central and the South/East regions (10\%, $14 \%$ and $18 \%$, respectively, all in 2006). In all regions, there was little change in the level of unmet need between 1997 and 2006.

The total fertility rate has declined sharply since the mid-1970s-from 5.6 children per woman in 1976 to 3.4 in 1990 to 2.2 in $2006 .{ }^{31,41}$ This is equivalent to a decline of 3.4 children per woman over the entire 30-year period. The drop between 1990 and 2006 was substantial (1.2 children on average) and occurred as the abortion rate rose. However, even after this decline, in 2006, slightly more than one-quarter of currently pregnant women reported that their pregnancy was unintended (Table 5).

Using the ENADID surveys for 1997 and 2006, we also examined changes in contraceptive use among women aged 15-44 who were at risk of unintended pregnancy (i.e., women who did not want a child soon, were currently in a union, were not pregnant and considered themselves to be fecund). About $84 \%$ of these women reported using contraceptives in both years (not shown). However,

*The measure of unmet need was developed by Macro International, Inc., for the Demographic and Health Surveys. Because we did not use data from these surveys, our analysis used the variables that were the closest match to those used in the standard definition. As in the standard measure, our estimates referred only to currently married women, and we considered them to have an unmet need for contraception if they were fertile, were not using a modern or traditional method and did not want to have a child soon or wanted no more children.

†For 2006, data were available only for the Secretaría de Salud hospital system; for 1990, data were available only for the Instituto Mexicano de Seguridad Social hospital system (each accounts for a large proportion of the women treated for postabortion complications). the method mix shifted: Reliance on female sterilization increased, while use of other effective modern methods (particularly the pill and the IUD) declined, but the proportion not using any method remained the same. After applying typical use failure rates to the proportions of women using each method, and assuming that $85 \%$ of women who were not using any method would become pregnant in the course of a year, we calculated that contraceptive protection-the proportion who would avoid becoming pregnant in a one-year period-hardly changed between 1997 and 2006 (81\% and 82\%, respectively).

\section{DISCUSSION}

In Mexico, as in Latin America and the Caribbean as a whole, unsafe abortion carries serious risks for women's health and survival..$^{42} \mathrm{~A}$ high proportion of women who have clandestine abortions in this region experience complications that need medical treatment, and in some countries, many of them require hospitalization. ${ }^{3,43}$ In Mexico, about one in six women who have abortions were hospitalized in 2006, just slightly less than the proportion in 1990 (one in five). The effect of expanded access to safer abortion methods (especially use of misoprostol ${ }^{22}$ ) in Mexico City and some of the states has likely been partially offset by an increase in the abortion rate and better access to hospital care. In addition, women who use misoprostol often prefer (or are advised) to have the abortion completed at a hospital once bleeding begins. ${ }^{44}$

It is also likely that the severity of abortion-related complications is currently somewhat less serious than before. In 2006, about four in 10 of all postabortion cases were treated in either the emergency room or the outpatient department, while most cases were treated on an inpatient basis. The average length of stay in 2006 for relatively uncomplicated postabortion cases was 0.8 day, if we assume that women who were not admitted as inpatients spent a fraction of a day at the facility (estimated to be 0.33 day on average). ${ }^{44}$ By comparison, in 1990, when women with abortion complications were almost all admitted as inpatients, the average length of stay for uncomplicated cases was 1.2 days. ${ }^{\dagger}$ While some of this difference is likely to have resulted from a reduction in the severity of complications, some of it could also be due to administrative and medical practice in the 1990s that required longer hospital stays, regardless of the severity of complications. ${ }^{7}$

The induced abortion rate in Mexico in 2006-33 per 1,000 women of reproductive age-is a relatively high level by worldwide standards, where abortion incidence is estimated to be 29 in developing countries overall. ${ }^{8}$ The rate has increased substantially over the past 16 years, despite the high prevalence of modern contraceptive use. In addition, an overall measure of contraceptive protection among women at risk of an unintended pregnancy hardly changed between 1997 and 2006. Combined with the decline in the total fertility rate, these results suggest that women who experience unplanned pregnancies have increasingly resorted to abortion. 
One explanation for this is that motivation to regulate fertility has increased at a faster pace than contraceptive use throughout the country. The fertility rate declined by 37\% between 1990 and 2006, while contraceptive use increased by only 12\% between 1992 and 2006. Another factor is that the ability of women and their partners to achieve the desired timing of births may be an even greater challenge now, given that women want only about two children. Attaining this goal would require that they be effective contraceptors for 20-25 years of their reproductive lives, unless they choose to be sterilized at a relatively young age. Since the mean age at sterilization in Mexico is about 29 years, the average woman would have to practice contraception successfully for 10-15 years to avoid having any unplanned pregnancies. In addition, women in Mexi$\mathrm{co}$, as in other countries where gender equity is not the norm, face difficulties negotiating effective contraceptive use with their partners. ${ }^{45-48}$ Women also often have negative attitudes toward methods, as well as misperceptions about side effects, which may result in not using contraceptives or discontinuing use while still being at risk of unintended pregnancy. ${ }^{49}$ It is notable that the prevalence of sterilization is high and has increased over the past 14 years-from 31\% of currently married women in 1992 to $39 \%$ in $2006^{29,31}$ an indication of women's desire to limit their childbearing.

Another factor that may contribute to high levels of unintended pregnancy and abortion is the lower priority that now seems to be given to public-sector provision of family planning services. In 1973, Mexico initiated a policy to promote the reduction of fertility and established a strong and successful national family planning program. Although contraceptive services are now widely available throughout the country, the results of the present studythat about one in eight women currently have an unmet need for contraception-suggest that there are still important gaps in the provision of contraceptive services, and increased efforts are needed to improve the effectiveness of contraceptive use and to reduce nonuse. The national family planning program has made a major contribution to helping women and couples regulate their fertility in the 35 years of its existence, but it must continue to respond to people's changing needs. At the present time, there is a risk that service provision may even deteriorate, as support for the program has weakened under the current conservative government, which is strongly influenced by the Catholic Church. For example, multiple attempts have been made to withdraw governmental approval of emergency contraception since the present government came into power, although these attempts have so far been unsuccessful. In addition, although the division between state and church has been very clear in the past, the church is presently more visible on the political scene and in the media. ${ }^{47,48,50}$

Our results showed that despite some similarities, there are still important differences between regions of the country. Although the abortion rate was quite similar in three of the four regions, it was lower in the South/East, where women want a somewhat larger family, and the population is more rural, poorer, less educated and more indigenous than in the other regions. Moreover, despite having abortion rates similar to the national average, the Central and South/East regions have higher-than-average levels of unmet need for contraception (14\% and $18 \%$, respectively) and notably lower levels of overall contraceptive use and of modern method use.

\section{Policy Implications}

This study has several policy and programmatic implications. There is a critical need to improve contraceptive services and information for the general population, particularly in the Central and South/East regions. Services need to be adapted to the current situation: In the early 1970s, when the national family planning program was initiated, the main concern was to raise awareness of the benefits of small families, of using contraceptives and of responsible parenthood. Currently, women and couples want to control their family size and want to use contraceptive methods, but they are failing to achieve their desired timing and number of births.

One important means of reducing the rates of unintended pregnancy and abortion is to provide high-quality postabortion contraceptive services. All abortion clients (both postabortion clients and induced abortion clients) should be offered a method at the time of service, and if they desire one, should be able to obtain a method on site. Immediate delivery of methods has been shown to be a highly effective approach: A number of studies in Africa and Latin America (including Mexico) have demonstrated high acceptance of contraception by women when they are offered a method at the time of service. ${ }^{51-53}$ This is an efficient means of reaching this group of women, who are strongly motivated to regulate their childbearing, and who are having difficulties preventing unintended pregnancies.

Other studies have suggested that special attention should be paid to two subgroups-men and adolescents. In Mexico, where gender equity is not the norm, women face difficulties in negotiating effective contraceptive use with their partners. ${ }^{45,46,49}$ These researchers recommended that efforts be made to provide information to husbands and male partners directly, and to raise awareness of the importance of effectively using contraceptives for preventing unintended pregnancies and for achieving desired timing of births. However, given how little is known in this area, more research is needed to improve our understanding of couples' incorrect and inconsistent contraceptive use, as well as their nonuse.

Adolescents have received little research attention regarding sex education (which, in Mexico, is not offered in schools), the services available to them and instruction about contraceptive methods in general, and particularly about correct use of the condom. ${ }^{54-56}$ At the same time, young people are marrying somewhat later than their par- 
ents did, and physical maturation is occurring at an increasingly younger age, ${ }^{.57}$ hence the average young adult experiences a longer period in which they may be sexually active before marriage. If the information and services provided to young people do not improve, it is likely that their sexual and reproductive heath will suffer, and that the rate of unwanted pregnancies and induced abortions will rise.

Broadening of the criteria under which abortion is legal is clearly a prerequisite to achieving access to legal and safe services. The recent liberalization of the abortion law (April 24, 2007) in Mexico City was a major achievement. However, access to safe and legal abortion is still extremely limited in the rest of the country, and there is an urgent need to improve and equalize access to safe abortion in these areas. The Mexico City government has begun to implement the provision of safe and comprehensive abortion care under the new law, and much can be learned by monitoring progress in implementation, barriers that are encountered and approaches that work (e.g., regarding service capacity and training and resource needs). In addition, regulatory approval for the use of mifepristone is needed in Mexico City; introduction of the World Health Organization-approved medical abortion regimen-combining mifepristone and misoprostol-for early legal abortions has the potential to further reduce the incidence of complications associated with unsafe abortion. ${ }^{58}$ Provision of accurate information on the dosage and timing of misoprostol alone would also limit the medical complications associated with this method.

\section{Conclusions}

Our findings bridge a 16-year data gap between 1990 and 2006 on induced abortion incidence and related morbidity in Mexico, and for the first time provide data for the country's major regions. The study also takes into account, to the extent possible, the increased use of misoprostol to induce abortion. The increase in the national abortion rate observed between 1990 and 2006 indicates that the need for preventing unintended pregnancy has increased faster than effective contraceptive use. The findings confirm the need for continued attention to prioritizing improvements in the provision of contraceptive services to achieve more continuous and consistent use among couples in Mexico. They also reinforce the importance of high-quality postabortion care-including contraceptive counseling and services-given that each year about 150,000 women are hospitalized for conditions resulting from induced abortion. The lack of a decline in the rate of abortionrelated hospitalizations over the past 16 years confirms that even in Mexico, a middle-income country with relatively favorable public health indicators, unsafe abortion remains a substantial burden to countless Mexican women and their families, and to the public-health sector. Continued research efforts to better understand the impact of unsafe abortion on women, families and the health sector are greatly needed.

\section{REFERENCES}

1. World Health Organization (WHO), Unsafe Abortion: Global and Regional Estimates of the Incidence of Unsafe Abortion and Associated Mortality in 2003, fifth ed., Geneva: WHO, 2007.

2. WHO, The Prevention and Management of Unsafe Abortion: Report of a Technical Working Group, Geneva: WHO, 1992.

3. Grimes DA et al., Unsafe abortion: the preventable pandemic, Lancet, 2006, 368(9550):1908-1919.

4. Singh S, Hospital admissions resulting from unsafe abortion: estimates from 13 developing countries, Lancet, 2006, 368(9550): 1887-1892

5. Levin C, Grossman D and Garcia SG, Unsafe abortion costs in Mexico City, ID21 Health Focus, Aug. 2007, p. 2.

6. Lafaurie MM, Grossman D and Troncoso E, El Aborto con Medicamentos en América Latina: Las Experiencias de las Mujeres en México, Colombia, Ecuador y Perú, 2005, <http://www.ipas.org/ Publications/asset_upload_file753_2826.pdf>, accessed Apr. 9, 2008.

7. Johnson BR et al., Costs and resource utilization for the treatment of incomplete abortion in Kenya and Mexico, Social Science $\&$ Medicine, 1993, 36(11):1443-1453.

8. Sedgh G et al., Induced abortion: estimated rates and trends worldwide, Lancet, 2007, 370(9595):1338-1345.

9. Singh S, Prada E and Kestler E, Induced abortion and unintended pregnancy in Guatemala, International Family Planning Perspectives, 2006, 32(3):136-145.

10. Chambers VM, Abordando la calidad de atención del aborto y la planificación familiar post-aborto, in: Maternidad sin Riesgos en México, Mexico City: Comité Promotor de la Iniciativa por una Maternidad sin Riesgos en México, 1994, pp. 167-176.

11. Juarez F, Certificación del proceso de generación de estadísticas sobre mortalidad materna, in: Zúñiga E, ed., Certificación Internacional del Programa Arranque Parejo en la Vida y Certificación del Proceso de Generación de Estadísticas Sobre Mortalidad Materna, Mexico City: Centro Nacional de Equidad de Género y Salud Reproductiva, Secretaría de Salud, 2006

12. Healy J, Otsea K and Benson J, Counting abortions so that abortion counts: indicators for monitoring the availability and use of abortion care services, International Journal of Gynecology $\&$ Obstetrics, 2006, 95(2):209-220

13. Rossier C, Estimating induced abortion rates: a review, Studies in Family Planning, 2003, 34(2):87-102.

14. Núñez L, El aborto en México y líneas de investigación para su estudio, paper presented at the IUSSP General Conference, Tours, France, July 18-23, 2005.

15. Lara D et al., The measure of induced abortion levels in Mexico using random response technique, Sociological Methods and Research, 2006, 35(2):279-301

16. Singh S and Wulf D, Estimated levels of induced abortion in six Latin American countries, International Family Planning Perspectives, 1994, 20(1):4-13

17. Sathar Z, Singh S and Fikree FF, Estimating the incidence of abortion in Pakistan, Studies in Family Planning, 2007, 38(1):11-22.

18. Singh S, Prada E and Juárez F, The health facilities complications method for estimating abortion incidence: how has it worked, and how can it be improved?, paper presented at the IUSSP Seminar on Measurement of Abortion Incidence, Abortion-Related Morbidity and Mortality, Paris, Nov. 7-9, 2007.

19. Juarez $\mathrm{F}$ et al., The incidence of induced abortion in the Philippines: current levels and recent trends, International Family Planning Perspectives, 2005, 31(3):140-149.

20. Singh S, Prada E and Mirembe KF, The incidence of induced abortion in Uganda, International Family Planning Perspectives, 2005, 31(4):183-191.

21. Henshaw $S$ et al., The incidence of induced abortion in Nigeria, International Family Planning Perspectives, 1998, 24(4):156-164. 
22. Lara D et al., Using multiple data sources to understand the impact of misoprostol on reports of abortion complications in Mexican hospitals, paper presented at the IUSSP Seminar on Measurement of Abortion Incidence, Abortion-Related Morbidity and Mortality, Paris, Nov. 7-9, 2007.

23. Pick $S$ et al., Pharmacists and market herb vendors: abortifacient providers in Mexico City, in: Mundigo A and Indriso C, eds., Abortion in the Developing World, London: Zed Books, 1999, pp. 293-310.

24. Clark W, Shannon C and Winikoff B, Misoprostol for uterine evacuation in induced abortion and pregnancy failure, Expert Review of Obstetrics and Gynecology, 2007, 2(1):67-108.

25. Lara D, Assessing pharmacy provision of misoprostol in Mexico using mystery client methodology, paper presented at the annual meeting of the National Abortion Federation, Minneapolis, MN, USA, Apr. 5-7, 2008

26. Villavicencio E, National sales of abortifacient drugs in Mexico, unpublished tabulations, Mexico City, Oct. 2007.

27. Dirección General de Información en Salud, Sistema Nacional de Información en Salud, Mexico City, hospital data, 2006

28. Consejo Nacional de Población (CONAPO), Índices de Marginación, 2000, Mexico City: CONAPO, 2000.

29. Instituto Nacional de Estadística, Geografía e Informática (INEGI), Encuesta Nacional de Dinámica Demográfica, 1992, Aguascalientes, Mexico: INEGI, 1992.

30. INEGI, Encuesta Nacional de Dinámica Demográfica, 1997, Aguascalientes, Mexico: INEGI, 1997.

31. CONAPO, Encuesta Nacional de Dinámica Demográfica, 2006 Mexico City: CONAPO, 2006.

32. Bongaarts J and Potter R, Fertility, Biology and Behavior, New York: Academic Press, 1983

33. Special tabulations from Encuesta Nacional de Dinámica Demográfica, 2006.

34. INEGI, IX Censo de Población y Vivienda, 1970, Aguascalientes, Mexico: INEGI, 1972.

35. INEGI, XII Censo de Población y Vivienda, 2000, Aguascalientes, Mexico: INEGI, 2003.

36. Secretaría de Programación y Presupuesto and Instituto de Investigaciones Sociales de la UNAM (SPP-IISUNAM), Encuesta Mexicana de Fecundidad, 1979, Mexico City: SPP-IISUNAM, 1979.

37. Special tabulations from Encuesta Nacional de Dinámica Demográfica, 2006.

38. Gayet $\mathrm{C}$ et al., Condom use among Mexican adolescents to prevent sexually transmitted infections, Salud Pública de México, 2003, 45(Suppl. 5):S632-S640.

39. Menkes $C$ and Suárez L, Sexualidad y embarazo adolescente en México, Papeles de Población, 2003, 9(35):233-262.

40. Mendoza D, Planificación familiar: logros en la última década y retos futuros, in: Hoekman A, ed., La Situación Demográfica de México, 2006, Mexico City: CONAPO, 2007, pp. 49-64.

41. CONAPO, Situación Actual de la Mujer en México: Diagnóstico Sociodemográfico, Mexico City: CONAPO, 2000

42. Guillaume A and Lerner S, Abortion in Latin America and the Caribbean, CD-ROM, Mexico City: Centre Population et Developpement, 2007.

43. Paxman J et al., The clandestine epidemic: the practice of unsafe abortion in Latin America, Studies in Family Planning, 1993, 24(4):205-226.

44. Dr. Patricio Sanhueza, Coordinador de Salud Reproductiva, Secretaría de Salud del Gobierno del Distrito Federal, Mexico City, personal communication, May 12, 2008.

45. Amuchástegui A and Rivas M, Clandestine abortion in Mexico: a question of mental as well as physical health, Reproductive Health Matters, 2002, 10(19):95-102.

46. Erviti J, El Aborto Entre Mujeres Pobres: Sociología de la Experiencia,
Cuernavaca, Mexico: Centro Regional de Investigaciones Multidisciplinarias, Universidad Nacional Autónoma de México, 2005.

47. Lamas M and Bissell S, Abortion and politics in Mexico: "context is all," Reproductive Health Matters, 2000, 8(16):10-23.

48. Garcia SG et al., Policy implications of a national public opinion survey on abortion in Mexico, Reproductive Health Matters, 2004 12(24 Suppl. 1):65-74.

49. Juarez F, Contraception and abortion: the case of Mexico, paper presented at the Contraception and Abortion Meeting at the Bill and Melinda Gates Institute for Population and Reproductive Health, Johns Hopkins Bloomberg School of Public Health, Baltimore, MD, USA, Jan. 25-26, 2007.

50. Taracena R, Social actors and discourse on abortion in the Mexican press: the Paulina case, Reproductive Health Matters, 2002, 10(19):103110.

51. Solo J et al., Creating linkages between incomplete abortion treatment and family planning services in Kenya, Studies in Family Planning, 1999, 30(1):17-27.

52. Benson J and Billings D, Postabortion care in Latin America: policy and service recommendations from a decade of operations research, Health Policy and Planning, 2005, 20(3):158-166.

53. Johnson BR et al., Reducing unplanned pregnancy and abortion in Zimbabwe through postabortion contraception, Studies in Family Planning, 2002, 33(2):195-202.

54. Menkes C et al., La Salud Reproductiva de los Estudiantes de Educación Superior, de Chiapas, Guanajuato, Guerrero, Puebla y San Luis Potosí, Cuernavaca, Mexico: Centro Regional de Investigaciones Multidisciplinarias, Universidad Nacional Autónoma de México, 2006.

55. Welti C, Las encuestas nacionales de fecundidad en México y la aparición de la fecundidad adolescente como tema de investigación, Papeles de Población, 2006, 12(50):253-275.

56. Juarez F and Gayet C, Salud sexual y reproductiva de los adolescentes en México: un nuevo marco de análisis para la evaluación y diseño de políticas, Papeles de Población, 2005, 11(45):177-219.

57. Malina RM et al., Secular change in age at menarche in rural Oaxaca, southern Mexico: 1968-2000, Annals of Human Biology, 2004 31(6):634-646

58. WHO, Safe Abortion: Technical and Policy Guidance for Health Systems, Geneva: WHO, 2003.

\section{RESUMEN}

Contexto: En México, donde el aborto inducido en gran parte continúa siendo ilegal y clandestino, el contar con datos confiables sobre su incidencia y la morbilidad relacionada es crítico para fundamentar las políticas y programas. La única estimación nacional disponible sobre aborto es para 1990; y, desde entonces, los cambios demográficos y socioeconómicos probablemente han afectado su incidencia.

Métodos: El estudio usó estadísticas oficiales sobre mujeres que recibieron tratamiento por complicaciones relacionadas con el aborto en hospitales públicos en 2006; y datos de una encuesta aplicada a profesionales de salud, informados en el tema. Se utilizó técnicas de estimación indirecta para calcular medidas de aborto nacionales y regionales, las cuales se compararon con las estimaciones de 1990

Resultados: En 2006, un número estimado de 150,000 mujeres recibieron tratamiento por complicaciones de aborto inducido en hospitales del sector público; y se estimó que una de cada 5.8 mujeres que tuvieron un aborto inducido recibió dicho tratamiento. El numero total estimado de abortos inducidos en 2006 fue de 875,000; y la tasa de aborto fue de 33 por 1,000 mujeres de 15-44 años. Entre 1990 y 2006, la tasa de aborto 
aumento en 33\% (de una tasa de 25). La severidad de la morbilidad debida al aborto inseguro disminuyó (como se observó a través de estancias más cortas en el hospital), pero no así la tasa anual de hospitalización-que fue de 5.4 por 1,000 mujeres en 1990 y 5.7 en 2006. La tasa de aborto fue similar al promedio nacional en tres regiones (34-36), pero sustancialmente menor en una de ellas (25 en la región Sureste).

Conclusiones: En México, el aborto clandestino continúa afectando negativamente la salud de las mujeres. Las acciones recomendadas incluyen la ampliación de los criterios legales para el aborto en todo México, el mejoramiento de los servicios de anticoncepción y postaborto, así como la expansión de la capacitación relacionada con la provisión del aborto seguro, incluido el aborto médico.

\section{RÉSUMÉ}

Contexte: Au Mexique, où l'avortement demeure largement illégal et clandestin, la disponibilité de données fiables sur l'IVG et la morbidité afférente est essentielle à l'élaboration des politiques et des programmes. La seule estimation nationale disponible sur la question remonte à 1990. L'évolution démographique et socioéconomique a depuis lors vraisemblablement affecté l'incidence de l'avortement.

Méthodes: Cette étude repose sur les statistiques officielles relatives aux femmes traitées pour complications d'un avortement dans les hôpitaux de l'état en 2006 et sur les données d'une enquête menée auprès des professionnels de la santé informés sur la question. Les techniques d'estimation indirecte ont servi à calculer les mesures d'avortement nationales et régionales, par rapport aux estimations de 1990.

Résultats: Pour l'année 2006, on estime à 150.000 le nombre de femmes traitées pour complications d'un avortement provoqué dans les hôpitaux du secteur public. Une femme avortée sur 5,8 aurait, selon les estimations, reçu un tel traitement. Le nombre total d'IVG pratiquées en 2006 est estimé à 875.000, soit un taux d'avortement de 33 pour 1.000 femmes âgées de 15 à 44 ans. Entre 1990 et 2006, le taux d'avortement a augmenté de 33\% (sur un taux de 25 pour 1.000). La gravité de la morbidité imputable à l'avortement non médicalisé a baissé (comme l'indique la moindre durée des séjours à l'hôpital), mais le taux d'hospitalisation annuel a, lui, augmenté, passant de 5,4 pour 1.000 femmes en 1990 à 5,7 en 2006. Le taux d'avortement est comparable à la moyenne nationale dans trois régions (34-36 pour 1.000), mais il est nettement plus faible dans celle du sud-est (25 pour 1.000).

Conclusions: L'avortement clandestin continue à affecter négativement la santé des Mexicaines. Les réponses recommandées sont l'élargissement des critères d'avortement légal dans l'ensemble du pays, l'amélioration des services contraceptifs et post-avortement, ainsi qu'une formation accrue à la prestation de l'avortement sans risque, y compris l'avortement médicalisé.

\section{Acknowledgments}

The authors thank independent consultants Xipatl Contreras, Diana Lara, Jorge A. Valencia and Karla Berdichevsky for invaluable contributions to study design, data collection and analysis; and Laura Carrillo, Alyssa Tartaglione and Katherine Wilson for research support. Dr. Luis Manuel Torres, Subdirector de Clasificación de Información en Salud, Dirección General de Información en Salud, provided guidance on data quality and coding of hospital statistics; and the federal, Mexico City and other statelevel ministries of health endorsed the project, enabled access to secondary health facilities data and provided technical input. The authors are also grateful to study participants and to the organizations and institutions that provided guidance and feedback throughout the study. This research was supported by an anonymous donor and the William and Flora Hewlett Foundation. The conclusions and views expressed here are those of the authors and not necessarily those of the funders.

Author contact:ssingh@guttmacher.org 